\title{
Evaluation of Bacterial Coinfection and Antibiotic Resistance in Patients with COVID-19 Under Mechanical Ventilation
}

\author{
Alireza Nikzad Jamnani ${ }^{1} \cdot$ Mahbobeh Montazeri $^{2} \cdot$ Maryam Mirzakhani $^{3} \cdot$ Mahmood Moosazadeh $^{4}$. \\ Mohammad Haghighi ${ }^{5}$
}

Accepted: 28 December 2021 / Published online: 6 January 2022

(c) The Author(s), under exclusive licence to Springer Nature Switzerland AG 2022

\begin{abstract}
Patients with confirmed SARS-CoV-2 are principally at risk of emerging superinfections, particularly those caused by Gram-negative bacteria. Therefore, in this retrospective cohort study, we investigated the presence of bacteria in endotracheal aspirate samples in severe COVID-19 patients under mechanical ventilation between 20 February 2020 and 21 September 2020 in Mazandaran Heart Center Hospital, Iran. Outcomes were compared between ICU patients with confirmed SARS-CoV-2 (corona group) and those who suffer from other disease (non-corona group). Out of 38 subjects who met the diagnostic criteria for ventilator-associated pneumonia (VAP) in ICU, 22 and 16 patients in corona and non-corona groups, respectively, were enrolled in the study. Hospital length of stay in $27 \%$ of case in corona group was $>10$ days. Also, SOFA score was $>10$ in $64 \%$ and $25 \%$ of corona and non-corona groups, respectively $(P<0.05)$. Moreover, the number of death was significantly higher among corona patients $(45 \%)$ than non-corona group $(6 \%)$ in ICU $(P<0.05)$. Acinetobacter spp. were the most common bacteria in nine corona patients (41\%) that were $100 \%$ resistant to amikacin, gentamycin, cefixime, and imipenem antibiotics. The prevalence of antibiotic resistance among pathogens isolated from patients with COVID-19 under mechanical ventilation in ICU highlighted the importance of preventing coinfections caused by this pathogen, suggesting an essential standardized approach to antibiotic stewardship in patients with COVID-19 for successful treatment.
\end{abstract}

Keywords SARS-CoV-2 $\cdot$ Ventilator-associated pneumonia $\cdot$ Bacterial coinfection $\cdot$ Antibiotic resistance

Mahbobeh Montazeri

m.montazeri2012@yahoo.com

1 Department of Anesthesiology and Critical Care, Mazandaran Heart Center, Mazandaran University of Medical Sciences, Sari, Iran

2 Toxoplasmosis Research Center, Communicable Diseases Institute, Iranian National Registry Center for Lophomoniasis and Toxoplasmosis, Mazandaran University of Medical Sciences, PO Box 48471-91971 Sari, Iran

3 Mazandaran Heart Center, Mazandaran University of Medical Sciences, Sari, Iran

4 Health Sciences Research Center, Addiction Institute, Mazandaran University of Medical Sciences, Sari, Iran

5 Anesthesia Research Center, Guilan University of Medical Sciences, Rasht, Iran

\section{Introduction}

SARS-CoV-2, first identified in Wuhan, China, is responsible for the illness named coronavirus disease 2019 (COVID19 ), which has quickly become epidemic worldwide in the twenty-first century with high rate of mortality and morbidity [1-3]. This new pathogen is a beta coronavirus, which arrives into the lungs and heart, kidney, or gastrointestinal cells by fusion with human angiotensin-converting enzyme 2 (ACE2) receptor, and the spike protein of SARS-CoV-2 with a functional polybasic cleavage site plays a vital role in this [4]. The symptoms of disease are associated with age, immune system status, and patient's underlying disease ranged from asymptomatic/mildly symptomatic emersions to acute respiratory failure with higher mortality [5-7]. In case of severe COVID-19 disease due to respiratory failure, patients requiring ventilation support by mechanical ventilation and endotracheal intubation and outstripping the intensive care unit (ICU) bed valence in the most affected 
countries that increased risk to acquire bacterial ICU-pneumonia in this condition [8].

The previous studies reported that secondary bacterial infections, particularly with Streptococcus pneumoniae, Haemophilus influenzae, and Staphylococcus aureus increased in pneumonitis epidemics and pandemics [9-11]. Based on a systematic review, bacterial coinfections were detected in $7 \%$ and $14 \%$ of COVID-19 hospitalized cases and ICU patients, respectively. In these patients, bacterial coinfection was reported as a predictor of mortality [12]. Also, secondary bacterial infections were reported in $15 \%$ of hospitalized adult patients from COVID-19 cases in Wuhan [13]. Furthermore, it is known that the mortality rate can be up to $60 \%$ when ventilator-associated pneumonia (VAP) is caused by MDR pathogens [14].

Given that COVID-19 disease is a growing problem with implications for worldwide health and economy, the diagnosis and antimicrobial resistance pattern of bacterial coinfection are essential to ensure a better clinical outcome in these cases [15]. Therefore, in this survey, we investigated the presence of bacteria in endotracheal aspirate samples in severe COVID-19 patients under mechanical ventilation in Mazandaran Heart Center Hospital, Iran.

\section{Subjects and Methods}

\section{Study Population and Data Collection}

This retrospective cohort study was approved by the joint Ethical Committees of Mazandaran University of Medical Sciences, Sari, Iran (Ethics No. IR.MAZUMS. REC.1399.8461). Patients with confirmed SARS-CoV-2 under mechanical ventilation hospitalized in ICU between 20 February 2020 and 21 September 2020 in Mazandaran Heart Center Hospital, Sari, Iran, were included in the current study as corona group. The patients under mechanical ventilation in ICU suffering from other disease in this period were considered non-corona group. According to the clinical guidelines (version 5) by Scientific Committee of the Iran's National Headquarters of COVID-19 Disease Management, $\mathrm{SpO} 2<93 \%$ or RR $>30$, fever $\geq 37.8^{\circ} \mathrm{C}$, computed tomography (CT) scan with radiographic abnormalities in the lung, positive real-time PCR, lymphopenia, and positive results of C-reactive protein (CRP) were considered the diagnostic criteria of COVID-19 [16]. VAP is defined in these patients as severe pneumonia happening more than $48 \mathrm{~h}$ after the initiation of invasive mechanical ventilation [17].

Quantitative culture techniques for tracheal secretion aspirates are more reliable if appropriate cutoff criteria are applied. When patients experience pneumonia, pathogens are available in the lower respiratory tract secretions at concentrations of at least $10^{5}$ to $10^{6} \mathrm{CFU} / \mathrm{ml}$. The current diagnostic threshold proposed for tracheal aspirate is $10^{6} \mathrm{CFU} / \mathrm{ml}$ [18].

In this study, endotracheal aspirate specimens were obtained during routine clinical specimen collection evaluated immediately after assembly according to the clinical and laboratory standard institute (CLSI) instructions in the hospital's microbiology laboratory [19].

\section{Statistical Analysis}

All data were expressed as number (\%) and compared by Fisher's exact test. Differences were considered statistically significant when $P<0.05$. Demographic, clinical, and laboratory data at admission were used to calculate SOFA for the prediction of mortality risk in ICU patients [20].

\section{Results}

Out of 38 patients under mechanical ventilation hospitalized in ICU from 20 February 2020 to 21 September 2020, a total of 22 patients in corona group meet the diagnostic criteria for VAP, were included in the study and compared with a total of 16 patients in non-corona group in Mazandaran Heart Center Hospital, Sari, Iran. Sixty-eight percent of patients was female in corona groups. Hospital length of stay in $27 \%$ of case in corona group was $>10$ days. Also, SOFA score was $>10$ in $64 \%$ and $25 \%$ of corona and non-corona groups, respectively $(P<0.05)$. Moreover, the number of death was significantly higher among corona patients (45\%) than non-corona group (6\%) in ICU $(P<0.05)$ (Table 1).

In this study, most of the isolated bacteria were Acinetobacter spp. (41\%) in corona group. The other organisms in this group were Pseudomonas aeruginosa (9.1\%), Klebsiella spp., E. coli, Staphylococcus aureus, Staphylococcus epidermis (4.5\%), Candida spp. (18.2\%), and diphtheroid (13.6\%) in corona patients (Table 2). In non-corona group, 8 patients were found negative for bacterial infections in endotracheal aspirate specimen culture. The organisms in this group were Acinetobacter spp. (4 patients), Klebsiella spp. (2 patients), and Candida spp. (2 patients). There was no significant difference between the corona and non-corona groups according to the microbiologic culture results $(P>0.5)$.

In our study, Acinetobacter spp. were $100 \%$ resistant to amikacin, gentamycin, cefixime, and imipenem. Pseudomonas aeruginosa was more resistant to co-trimaazol and cefixime. Also, Klebsiella spp. were $100 \%$ resistant to cotrimaazol, cefixime, amikacin, gentamycin, ciprofloxacin, and ceftazidime. Moreover, E. coli was $100 \%$ resistant to cotrimaazol and cefixime in corona group (Table 2). Furthermore, Acinetobacter spp. and Klebsiella spp. were resistant to almost all antibiotics used with the exception of colistin in non-corona group. 
Table 1 Comparison of demographic features, risk factors, and clinical characteristics in corona and non-corona groups (data are the number)

\begin{tabular}{|c|c|c|c|}
\hline Variables & $\begin{array}{l}\text { Corona group } \\
(N=22)\end{array}$ & $\begin{array}{l}\text { Non-corona group } \\
(N=16)\end{array}$ & $P$-value \\
\hline \multicolumn{4}{|l|}{ Gender } \\
\hline Male & $7(32)$ & $3(19)$ & \multirow[t]{2}{*}{0.469} \\
\hline Female & $15(68)$ & $13(81)$ & \\
\hline \multicolumn{4}{|c|}{ Age group (years) } \\
\hline $40-50$ & $2(9)$ & $1(6)$ & \multirow{4}{*}{0.370} \\
\hline $50-60$ & $3(14)$ & $3(19)$ & \\
\hline $60-70$ & $6(27)$ & $4(25)$ & \\
\hline$>70$ & $11(50)$ & $8(50)$ & \\
\hline \multicolumn{4}{|c|}{ Length of stay (days) } \\
\hline$<10$ & $16(73)$ & $8(50)$ & \multirow[t]{2}{*}{0.187} \\
\hline$>10$ & $6(27)$ & $8(50)$ & \\
\hline Positive PCR & $9(41)$ & - & - \\
\hline \multicolumn{4}{|l|}{ SOFA } \\
\hline$<10$ & $8(36)$ & $12(75)$ & \multirow[t]{3}{*}{0.040} \\
\hline $10-20$ & $12(54)$ & $4(25)$ & \\
\hline$>20$ & $2(10)$ & & \\
\hline \multicolumn{4}{|l|}{ Final outcome } \\
\hline Recovery & $12(55)$ & $15(94)$ & \multirow[t]{2}{*}{0.012} \\
\hline Death & $10(45)$ & $1(6)$ & \\
\hline
\end{tabular}

${ }^{a}$ All patients with confirmed SARS-CoV-2 infection

${ }^{\mathrm{b}}$ All patients suffering from other disease

\section{Discussion}

Patients with confirmed SARS-CoV-2 are principally at risk of emerging superinfections, particularly those caused by Gram-negative bacteria with MDR infections [21]. However, the pattern of coinfections and the microbiological profile in these cases remain an essential information gap in the literature [22]. To reveal this aspect, we investigated microbiologic data from 22 severe COVID-19 patients under mechanical ventilation. Based on the result of this study, $59.1 \%$ of patients in corona group showed the presence of Gram-negative bacteria, where Acinetobacter spp. and Pseudomonas aeruginosa were the most common species, respectively.

Mazzariol et al., Zhang et al., and Chen et al. reported $58.1 \%, 29.8 \%$, and $5.1 \%$ of bacterial coinfections/superinfection in COVID-19 patients [15, 23, 24]. Based on previous study from Nahavand Hospitals, Hamedan, Iran, of 340 patients with COVID-19, secondary bacterial infections were reported in $12.46 \%$ of patients. The most common bacteria isolated were Klebsiella species, S. aureus, and E. coli. [25]. Also, Sharifipour et al. reported that of 19 positive corona cases, admitted to ICUs in Qom, Iran, 18 (95\%) of patients died. All patients were found positive for bacterial coinfections caused by Acinetobacter baumannii $(90 \%)$ and Staphylococcus aureus (10\%) [26]. Out of the 22 cases with severe COVID-19 in our survey, $45 \%$ died in ICU. These
Table 2 Resistance of bacteria to different classes of antibiotics associated to VAP in corona group patients

\begin{tabular}{|c|c|c|c|c|c|c|c|}
\hline \multirow{2}{*}{$\begin{array}{l}\text { Antibiotic } \\
\text { - }\end{array}$} & \multicolumn{7}{|c|}{$\begin{array}{l}\text { Microorganism } \\
\mathrm{N}(\%)\end{array}$} \\
\hline & $\begin{array}{l}\text { Acine- } \\
\text { tobacter } \\
\text { spp. } \\
9(41)\end{array}$ & $\begin{array}{l}\text { Pseu- } \\
\text { domonas } \\
\text { aeruginosa } \\
2(9.1)\end{array}$ & $\begin{array}{l}\text { Klebsiella spp. } \\
1(4.5)\end{array}$ & $\begin{array}{l}\text { E. coli } \\
1(4.5)\end{array}$ & $\begin{array}{l}\text { Staph. aureus } \\
1(4.5)\end{array}$ & $\begin{array}{l}\text { Staph. } \\
\text { epider- } \\
\text { midis } \\
1(4.5)\end{array}$ & $\begin{array}{l}\text { Others* } \\
7(31.8)\end{array}$ \\
\hline Ampicillin & NT & NT & NT & NT & 100 & 100 & NT \\
\hline Penicillin G & NT & NT & NT & NT & 100 & 100 & NT \\
\hline Cephalithin & NT & NT & NT & NT & NT & 100 & NT \\
\hline Clindamycin & NT & NT & NT & NT & 0 & 100 & NT \\
\hline Oxacillin & NT & NT & NT & NT & 0 & 100 & NT \\
\hline Vancomycin & NT & NT & NT & NT & 0 & 25 & NT \\
\hline Cefatriaxon & 50 & 75 & NT & 0 & NT & NT & NT \\
\hline Co-trimaazol & 50 & 100 & 100 & 100 & NT & NT & NT \\
\hline Cefixime & 100 & 100 & 100 & 100 & NT & NT & NT \\
\hline Amikacin & 100 & 25 & 100 & 0 & NT & NT & NT \\
\hline Gentamycin & 100 & 25 & 100 & 0 & NT & NT & NT \\
\hline Nitrofurantein & 100 & 25 & NT & 0 & NT & NT & NT \\
\hline Ciprofloxacin & 50 & 50 & 100 & 0 & NT & NT & NT \\
\hline Colistin & 50 & 25 & 0 & NT & NT & NT & NT \\
\hline Ceftazidime & 50 & NT & 100 & 0 & NT & NT & NT \\
\hline Imipenem & 100 & NT & NT & NT & NT & NT & NT \\
\hline
\end{tabular}

${ }^{*}$ Candida spp. 4 (18.2), diphtheroid 3 (13.6); NT not tested 
findings indicated a significant role of bacterial secondary infection in COVID-19 patients.

Evans et al. reported that overall mortality in ICU patients with COVID-19 under mechanical ventilation at the St George's Hospital, London, was 35\%. Most of ICU patients did not have bronchoalveolar lavages undertaken, and therefore bacterial coinfections in this study were not evaluated [27]. Based on Yang et al. study, the mortality rate was 32 cases in 37 critically ill patients with COVID-19 documented mechanical ventilation. Among the dead patients, secondary infections were reported in 4 cases with highly drug-resistant organisms [28].

One recent study by Temperoni et al. indicated that the MDR microorganisms were detected $64.5 \%$ in 48 COVID-19 patients under mechanical ventilation in ICU of Pesaro Hospital. Also, similar to our results, Gram-negative were more than Gram-positive bacteria in MDR strains. They detected a high prevalence of A. baumannii Carbapenem-resistant colonization with an infection rate of $75 \%$ [29]. Based on our findings, Acinetobacter spp. was $100 \%$ resistant to amikacin, gentamycin, cefixime, and imipenem antibiotics. Emergence of MDR Gram-negative bacteria are commonly associated to protracted use of external devices in patients such as urinary catheters, mechanical ventilation, central venous lines, to prolonged length of stay [30]. Drug-resistant bacteria present a serious threat to human health [28]. Montrucchio et al. evaluated Carbapenem-resistant Klebsiella pneumoniae (CP-Kp) in ICU-admitted COVID-19 individuals at "Città della Salute e della Scienza" hospital in Turin (Italy) from 1 March to 20 May 2020. In this study, bacterial coinfection was reported in three patients with VAP caused by Pseudomonas aeruginosa and Klebsiella pneumonia. Also, the mortality related to CP-Kp septic shock was $28.6 \%$ in these patients [31].

Recently, Mazzariol et al. reported that the most frequently isolated bacterial species in bronchial aspirate samples from mechanically ventilated patients with severe COVID-19 were Pseudomonas aeruginosa. The majority of these isolates showed Carbapenem resistance [15]. In other study, Grasselli et al. reported that in patients undergoing extracorporeal membrane oxygenation, colonization by multidrug-resistant-Gram-negative bacteria is common and is associated with more than ten-fold odds for following infections that are related with an increased risk of death [32]. Among Gram-positive bacteria, Staph. aureus and Staph. epidermidis were the most common species in patients. However, in Temperoni et al. survey, Staph. aureus, Staph. faecalis, and Staph. faecium were the most common species. Also, E. faecium showed to be MDR in $71.4 \%$ of the patients [29]. Moreover, emergence of Candida spp. was observed in $18.2 \%$ of cases. Senok et al. in evaluation of Dubai Health Authority hospitals and Sheikh Khalifa General Hospital Umm Al Quwain patients stated that predominance of
Gram-negative pathogens, emergence of Candida species, and prevalence of isolates harboring drug-resistance genes are of concern [33]. Eventually, a widespread consumption of antimicrobials, the immune dysregulation, and less adherence to the infection control and prevention measures are the main reasons of the high incidence of bacterial and fungal infections in severe COVID-19 cases [34].

\section{Conclusions}

The prevalence of antibiotic resistance among pathogens isolated from patients with COVID-19 under mechanical ventilation in ICU highlighted the importance of preventing coinfections caused by this pathogen, suggesting an essential standardized approach to antibiotic stewardship in patients with COVID-19 for successful treatment.

Author contribution ANJ, MM, and MMi designed the study. MMi provided patients' information and collected data. MM drafted the manuscript. MMO and MM analyzed the data. All authors read and approved the final manuscript.

Availability of data and material It will be available upon request.

Code availability Not applicable.

\section{Declarations}

Ethics approval This study was approved by the joint Ethical Committees of Mazandaran University of Medical Sciences, Sari, Iran (Ethics No. IR.MAZUMS.REC.1399.8461).

Consent to participate Not applicable.

Written consent for publication All authors agreed to publish this manuscript.

Conflict of interest The authors declare no competing interests.

\section{References}

1. Bassetti M, Vena A, Giacobbe DR. The novel Chinese coronavirus (2019-nCoV) infections: challenges for fighting the storm. Eur J Clin Invest. 2020;50:e13209.

2. Kinross P, Suetens C, Dias JG, Alexakis L, Wijermans A, Colzani E, Monnet DL. Rapidly increasing cumulative incidence of coronavirus disease (COVID-19) in the European Union/European Economic Area and the United Kingdom, 1 January to 15 March 2020. Euro Surveill. 2020;25(11):2000285.

3. Olsen SJ, Chen MY, Liu YL, Witschi M, Ardoin A, Calba C, Mathieu P, Masserey V, Maraglino F, Marro S, Penttinen P. Early introduction of severe acute respiratory syndrome coronavirus 2 into Europe. Em erg Infect Dis. 2020;26(7):1567. 
4. Zhao Y, Zhao Z, Wang Y, Zhou Y, Ma Y, Zuo W. Single-cell RNA expression profiling of ACE2, the receptor of SARS-CoV-2. Am J Respir Crit Care Med. 2020;202(5):756-9.

5. Baud D, Qi X, Nielsen-Saines K, Musso D, Pomar L, Favre G. Real estimates of mortality following COVID-19 infection. Lancet Infect Dis. 2020;20(7):773.

6. Mizumoto K, Kagaya K, Zarebski A, Chowell G. Estimating the asymptomatic proportion of coronavirus disease 2019 (COVID19) cases on board the Diamond Princess cruise ship, Yokohama, Japan. Euro Surveill. 2020;25(10):2000180.

7. Wang W, Tang J, Wei FJ. Updated understanding of the outbreak of 2019 novel coronavirus (2019-nCoV) in Wuhan, China. J Med Virol. 2020;92(4):441-7.

8. Remuzzi A, Remuzzi GJTl. COVID-19 and Italy: what next? Lancet. 2020. 395(10231):1225-1228.

9. Morris DE, Cleary DW, Clarke SCJ. Secondary bacterial infections associated with influenza pandemics. Front Microbiol. 2017;8:1041

10. Mulcahy ME, McLoughlin RMJM. Staphylococcus aureus and influenza A virus: partners in coinfection. MBio. 2016;7(6)

11. Rice TW, Rubinson L, Uyeki TM. Critical illness from 2009 pandemic influenza A (H1N1) virus and bacterial co-infection in the United States. Crit Care Med. 2012;40(5):1487.

12. Lansbury L, Lim B, Baskaran V, Lim WS. Co-infections in people with COVID-19: a systematic review and meta-analysis. J Infect. 2020;81(2):266-75.

13. Ruan Q, Yang K, Wang W, Jiang L, Song J. Clinical predictors of mortality due to COVID-19 based on an analysis of data of 150 patients from Wuhan, China. Intensive Care Med. 2020;46(5):846-8.

14. Cubillos-Zapata C, Avendaño-Ortiz J, Hernandez-Jimenez E, Toledano V, Casas-Martin J, Varela-Serrano A, et al. Hypoxiainduced PD-L1/PD-1 crosstalk impairs T-cell function in sleep apnoea. Eur Respir Rev. 2017;50(4).

15. Mazzariol A, Benini A, Unali I, Nocini R, Smania M, Bertoncelli A, De Sanctis F, Ugel S, Donadello K, Polati E. Dynamics of SARS-CoV2 infection and multi-drug resistant bacteria superinfection in patients with assisted mechanical ventilation. Front Cell Infect Microbiol. 2021;12(11):683409.

16. Rahmanzade R, Rahmanzadeh R, Hashemian SM, Tabarsi P. Iran's approach to COVID-19: evolving treatment protocols and ongoing clinical trials. Front Public Health. 2020;8:523.

17 Davis KAJ. Ventilator-associated pneumonia: a review. J Intensive Care Med. 2006;21(4):211-26.

18. Vincent JL, Abraham E, Kochanek P, Moore FA, Fink MP. Textbook of Critical Care E-Book. Elsevier Health Sciences; 2011.

19. Bobenchik AM, Deak E, Hindler JA, Charlton CL, Humphries RM. Performance of Vitek 2 for antimicrobial susceptibility testing of Acinetobacter baumannii, Pseudomonas aeruginosa, and Stenotrophomonas maltophilia with Vitek 2 (2009 FDA) and CLSI M100S 26th edition breakpoints. J Clin Microbiol. 2017;55(2):450-456.

20. Liu S, Yao N, Qiu Y, He C. Predictive performance of SOFA and qSOFA for in-hospital mortality in severe novel coronavirus disease. Am J Emerg Med. 2020;38(10):2074-80.

21. De Filippo O, D'Ascenzo F, Angelini F, Bocchino PP, Conrotto F, Saglietto A, Secco GG, Campo G, Gallone G, Verardi R, Gaido L. Reduced rate of hospital admissions for ACS during Covid-19 outbreak in Northern Italy. N Engl J Med. 2020;383(1):88-9.

22. Senok A, Alfaresi M, Khansaheb H, Nassar R, Hachim M, Al Suwaidi H, Almansoori M, Alqaydi F, Afaneh Z, Mohamed A.
Coinfections in patients hospitalized with COVID-19: a descriptive study from the United Arab Emirates. Infect Drug Resist. 2021;14:2289-96.

23. Zhang G, Hu C, Luo L, Fang F, Chen Y, Li J, Peng Z, Pan H. Clinical features and short-term outcomes of 221 patients with COVID-19 in Wuhan, China. J Clin Virol. 2020;127:104364.

24. Chen N, Zhou M, Dong X, Qu J, Gong F, Han Y, Qiu Y, Wang J, Liu Y, Wei Y. Epidemiological and clinical characteristics of 99 cases of 2019 novel coronavirus pneumonia in Wuhan, China: a descriptive study. Lancet. 2020;15;395(10223):507-13.

25. Mahmoudi $\mathrm{H}$. Bacterial co-infections and antibiotic resistance in patients with COVID-19. GMS Hyg Infect Control. 2020;15.

26. Sharifipour E, Shams S, Esmkhani M, Khodadadi J, Fotouhi-Ardakani R, Koohpaei A, Doosti Z, Golzari SE. Evaluation of bacterial co-infections of the respiratory tract in COVID-19 patients admitted to ICU. BMC Infect Dis. 2020;20(1):1-7.

27. Evans TJ, Davidson HC, Low JM, Basarab M, Arnold A. Antibiotic usage and stewardship in patients with COVID-19: too much antibiotic in uncharted waters? J Infect Prev. 2021;22(3):119-25.

28. Yang X, Yu Y, Xu J, Shu H, Liu H, Wu Y, Zhang L, Yu Z, Fang $\mathrm{M}, \mathrm{Yu}$ T. Clinical course and outcomes of critically ill patients with SARS-CoV-2 pneumonia in Wuhan, China: a single-centered, retrospective, observational study. Lancet Respir Med. 2020;8(5):475-81.

29. Temperoni C, Caiazzo L, Barchiesi F. High prevalence of antibiotic resistance among opportunistic pathogens isolated from patients with COVID-19 under mechanical ventilation: results of a single-center study. Antibiotics. 2021;10(9):1080.

30. Baiou A, Elbuzidi AA, Bakdach D, Zaqout A, Alarbi KM, Bintaher AA, Ali MM, Elarabi AM, Ali GA, Daghfal J. Clinical characteristics and risk factors for the isolation of multi-drug-resistant Gram-negative bacteria from critically ill patients with COVID19. J Hosp Infect. 2021;110:165-71.

31. Montrucchio G, Corcione S, Sales G, Curtoni A, De Rosa FG, Brazzi L. Carbapenem-resistant Klebsiella pneumoniae in ICUadmitted COVID-19 patients: keep an eye on the ball. J Glob Antimicrob Resist. 2020;23:398-400.

32. Grasselli G, Scaravilli V, Alagna L, Bombino M, De Falco S, Bandera A, Abbruzzese C, Patroniti N, Gori A, Pesenti A. Gastrointestinal colonization with multidrug-resistant Gram-negative bacteria during extracorporeal membrane oxygenation: effect on the risk of subsequent infections and impact on patient outcome. Ann Intensive Care. 2019;9(1):1-9.

33. Senok A, Alfaresi M, Khansaheb H, Nassar R, Hachim M, Al Suwaidi H, Almansoori M, Alqaydi F, Afaneh Z, Mohamed A, Qureshi S. Coinfections in patients hospitalized with COVID-19: a descriptive study from the United Arab Emirates. Infect Drug Resist. 2021;14:2289-96.

34. Cataldo MA, Tetaj N, Selleri M, Marchioni L, Capone A, Caraffa E, Di Caro A, Petrosillo N. Incidence of bacterial and fungal bloodstream infections in COVID-19 patients in intensive care: an alarming "collateral effect." J Glob Antimicrob Resist. 2020;23:290.

Publisher's Note Springer Nature remains neutral with regard to jurisdictional claims in published maps and institutional affiliations. 